\title{
Transcriptional activation of miR-320a by ATF2, ELK1 and YY1 induces cancer cell apoptosis under ionizing radiation conditions
}

\author{
ZHENG HU $^{1,2^{*}}$, YI TIE ${ }^{1 *}$, GUIXIANG LV ${ }^{1,3}$, JIE ZHU $^{1}$, HANJIANG FU $^{1}$ and XIAOFEI ZHENG ${ }^{1}$ \\ ${ }^{1}$ Beijing Key Laboratory for Radiobiology, Beijing Institute of Radiation Medicine, Beijing 100850; \\ ${ }^{2}$ Laboratory of Sono- and Photo-theranostic Technologies, Harbin Institute of Technology, Harbin, Heilongjiang 150080; \\ ${ }^{3}$ Department of Biochemistry and Molecular Biology, Harbin Medical University, Harbin, Heilongjiang 150086, P.R. China
}

Received February 7, 2018; Accepted July 6, 2018

DOI: $10.3892 /$ ijo.2018.4497

\begin{abstract}
MicroRNAs (miRNAs or miRs) play important roles in numerous cellular processes, including development, proliferation, tumorigenesis and apoptosis. It has been reported that miRNA expression is induced by ionizing radiation (IR) in cancer cells. However, the underlying molecular mechanisms are not yet fully understood. In this study, endogenous miR-320a and its primary precursor (pri-miR-320a) were assayed by reverse transcription-quantitative PCR (RT-qPCR). Luciferase activities were measured using a dual-luciferase reporter assay system. Western blot analysis was used to determine the protein expressions of upstream and downstream genes of miR-320a. Cell apoptosis was evaluated by Annexin $\mathrm{V}$ apoptosis assay and cell proliferation was measured using the trypan blue exclusion method. The results revealed that miR-320a expression increased linearly with the IR dose and treatment duration. Three transcription factors, activating transcription factor 2 (ATF2), ETS transcription
\end{abstract}

Correspondence to: Dr Xiaofei Zheng or Dr Hanjiang Fu, Beijing Key Laboratory for Radiobiology, Beijing Institute of Radiation Medicine, Beijing 100850, P.R. China

E-mail: xfzheng100@126.com

Email: fuhj75@126.com

*Contributed equally

Abbreviations: miRNA or miR, microRNA; IR, ionizing radiation; ATF2, activating transcription factor 2; ELK1, ETS transcription factor; YY1, YY1 transcription factor; MAPK, mitogen-activated protein kinase; JNK, mitogen-activated protein kinase 8; XIAP, X-linked inhibitor of apoptosis; 3'UTR, 3' untranslated region; RT-qPCR, reverse transcription-quantitative PCR; DMEM, Dulbecco's modified Eagle's medium; ChIP, chromatin immunoprecipitation; RIPA, radio-immunoprecipitation assay; SDS-PAGE, sodium dodecyl sulfate-polyacrylamide gel electrophoresis; ERK, p44/42 MAPK; TSS, transcriptional start site; SRE, serum response element; IAP, inhibitor of apoptosis

Key words: ionizing radiation, microRNA-320a, transcription factor, target gene, radiosensitivity factor (ELK1) and YY1 transcription factor (YY1), were activated by p38 mitogen-activated protein kinase (MAPK) and mitogen-activated protein kinase 8 (JNK) and by upregulated miR-320a expression under IR conditions. In addition, it was identified that $\mathrm{X}$-linked inhibitor of apoptosis (XIAP) was an miR-320a target gene during the IR response. By targeting XIAP, miR-320a induced apoptosis and inhibited the proliferation of the cancer cells. On the whole, the results of this study demonstrated that miRNA-320a, regulated by the p38 MAPK/JNK pathway, enhanced the radiosensitivity of cancer cells by inhibiting XIAP and this may thus prove to be a potential therapeutic approach with which to overcome radioresistance in cancer treatment.

\section{Introduction}

MicroRNAs (miRNAs or miRs) are small, single-stranded non-coding RNAs consisting of 21-23 nucleotides that regulate protein expression by pairing with the $3^{\prime}$ untranslated region (3'UTR) of target mRNAs (1). The role of miRNAs, which are associated with multiple facets of cellular activities, is one of the most important and exciting emerging paradigms in cell biology. Accumulating genetic evidence indicates that miRNAs also play an essential part in stress responses, such as hypoxia, hydrogen peroxide $\left(\mathrm{H}_{2} \mathrm{O}_{2}\right)$ and ionizing radiation (IR) (2-5). For example, it has been reported that several miRNAs are regulated by IR treatment $(6,7)$. The miRNAs, let-7, miR-34 and miR-16, have been identified to be upregulated in response to irradiation (8-10). Of note, the majority of these IR-induced miRNAs are also frequently dysregulated in cancer cells, and specific miRNAs are known to regulate both cell cycle progression and apoptosis $(11,12)$. These miRNAs may be predictive markers for clinical outcomes in human cancers or may be exploited to enhance sensitivity to radiotherapy, impede DNA double-strand break repair and induce chromosomal instability in $\gamma$-irradiated cells (13-15).

Radiotherapy, as the one of the three primary cancer treatment modalities, is used in approximately $50 \%$ of all cancer patients. It can disrupt cancer growth primarily by modulating several signal transduction pathways, causing DNA damage and enhancing tumor reaction to other therapies (16). However, the mechanisms underlying IR-induced miRNA expression and its possible effects are not yet well understood. 
In our previous study, miRNA expression profiles were analyzed in HeLa cells at $6 \mathrm{~h}$ following treatment with 8 Gy IR. Using reverse transcription-quantitative PCR (RT-qPCR), the expression levels of $21 \mathrm{miRNAs}$, including the let-7 family, miR-34a and miR-320a were found to be significantly altered (17).

miR-320a is an important miRNA and can regulate the expression of various target genes. For example, it has reported that survivin and c-Myc are suppressed by miR-320a $(18,19)$. Bronisz et al demonstrated that miR-320 functions as a critical component of the PTEN tumour-suppressor axis and curtailed tumour progression (20). We previously found that the expression of miR-320a was altered in HeLa cells treated with 8 Gy IR (17). However, the mechanisms through which miR-320a is regulated in response to IR and its target genes in this process remain unclear.

In the present study, we identified the promoter region of miR-320a and verified three transcription factors, activating transcription factor 2 (ATF2), ETS transcription factor (ELK1) and YY1 transcription factor (YY1), to be responsible for inducing miR-320a expression under IR conditions. We provided evidence identifying the novel miR-320a target gene, XIAP, and suggest that miR-320a enhances the radiosensitivity of cancer cells. We aim to further investigate whether such a regulation of miR-320a by IR occurs in vivo, and the possibility of whether miR-320a can be used as a radiation sensitizer in future studies.

\section{Materials and methods}

Cell culture conditions and treatments. Human uterine cervical cancer cells (HeLa) were cultured in RPMI-1640 (Thermo Fisher Scientific, Waltham, MA, USA) and human colon cancer cells (HCT116) were cultured in Dulbecco's modified Eagle's medium (DMEM) (Thermo Fisher Scientific) supplemented with $10 \%$ fetal bovine serum, penicillin and streptomycin. The cells were maintained at $37^{\circ} \mathrm{C}$ in the presence of $5 \% \mathrm{CO}_{2}$. The cells were plated in T-25 flasks and treated with IR at various doses $(0,1,3,5,8$ and $12 \mathrm{~Gy})$ following incubation at $37^{\circ} \mathrm{C}$ for $24 \mathrm{~h}$ to achieve logarithmic growth.

miRNAs, siRNAs and transfection. Synthetic miRNA mimics and siRNAs were obtained from GenePharma (Shanghai, China) (Table I). The HeLa and HCT116 cells were grown to $50 \%$ confluence in 6-well plates. The transfection of siRNAs and miRNAs was performed with jetPRIME (Polyplus, Illkirch, France) according to the manufacturer's instructions. The transfection medium was replaced with fresh medium after $6 \mathrm{~h}$ of incubation at $37^{\circ} \mathrm{C}$. Total RNA and protein were prepared at $48 \mathrm{~h}$ following transfection and used for RT-qPCR detection or western blot analysis. The p38 and JNK agonist, anisomycin (Ani), the p38 inhibitor, SB203580 (SB), and the JNK inhibitor, SP600125 (SP), were purchased from Sigma-Aldrich; Merck KGaA (Darmstadt, Germany) and dissolved in dimethyl sulfoxide (DMSO). The cells were respectively treated with Ani $(20 \mu \mathrm{M})$, SB $(10 \mu \mathrm{M})$, and SP $(20 \mu \mathrm{M})$ for $1 \mathrm{~h}$ prior to IR and harvested for western blot analysis after $24 \mathrm{~h}$ of incubation at $37^{\circ} \mathrm{C}$.

Plasmid constructs. The $1,000,800,500$ and $200 \mathrm{bp}$ fragment of the genomic sequence immediately upstream of the
miR-320a stem-loop structure were amplified by PCR from HeLa cell cDNA using Phusion DNA polymerase (Thermo Fisher Scientific). A pair of primers, including the XhoI and HindIII restriction sites were designed to amplify the miR-320a promoter inserts. The PCR products were cloned into the pGL3-enhancer vector (Promega, Madison, WI, USA).

Firstly, we searched the putative target sites of 3'UTR of XIAP by bioinformatics analysis using TargetScan (http://www.targetscan.org/) according to the instructions provided (http://www.targetscan.org/faqs.Release_7. $\mathrm{html}$ ). The 3'UTR of XIAP was then cloned into a modified pGL3-control plasmid (21) following the PCR amplification of genomic DNA. The coding sequences of ATF2, ELK1 and $Y Y 1$ were amplified from HeLa cell cDNA using a pair of primers, including the $A s c \mathrm{I}$ and $X h o \mathrm{I}$ restriction sites and were ligated into pCMV6-AN-3DDK. The pCMV6-3DDK-XIAP vector was purchased from Origene (Rockville, MD, USA). The primer sequences are presented in Table I. The sequences of all constructs were confirmed by DNA sequencing.

Quantification of miRNA and pri-miRNA. Total RNA was extracted from the cells using TRIzol reagent (Sigma-Aldrich; Merck KGaA) according to the manufacturer's instructions. miRNA quantification was performed using a Quantitect SYBR-Green PCR kit (Qiagen, Hilden, Germany). Reverse transcription followed by RT-qPCR was carried out using a high capacity cDNA reverse transcription kit (Thermo Fisher Scientific) as previously described by Fu et al (22). Specific primer sequences were designed according to miRBase 22.0 (http://www.mirbase.org/). For pri-miRNA quantification, RT-qPCR was performed according to mRNA quantitation method (23). GAPDH was used as an endogenous control. All qPCR experiments were carried out using the Mx3000p detection system (Agilent Technologies, Palo Alto, CA, USA). The PCR thermal cycle began at $95^{\circ} \mathrm{C}$ for $10 \mathrm{~min}$, followed by 40 cycles of $95^{\circ} \mathrm{C}$ for $15 \mathrm{sec}$ and $60^{\circ} \mathrm{C}$ for $1 \mathrm{~min}$. The primer sequences are presented in Table I. GenEX software version 5.0 was employed to analyze the qPCR data. One-way ANOVA with Dunnett's post hoc tests were performed to determine the difference in miRNA expression levels observed in the cells treated with IR at various doses $(0,1,3,5,8$ and $12 \mathrm{~Gy})$ and treatment times $(0,3,6,12,24,48$ and $72 \mathrm{~h})$.

Chromatin immunoprecipitation (ChIP). ChIP assays were carried out using a commercial kit from Cell Signaling Technology (CST, Danvers, MA, USA). Briefly, the cells were first fixed with $1 \%$ formaldehyde, and chromatin DNA was isolated with $1 \mu \mathrm{g}$ anti-ATF2 (sc-187X), $1 \mu \mathrm{g}$ anti-ELK1 (sc-355X), $1 \mu \mathrm{g}$ anti-YY1 (sc-1703X), or $1 \mu \mathrm{g} \mathrm{IgG} \mathrm{(sc-2027)}$ antibodies from Santa Cruz Biotechnology (Santa Cruz, CA, USA) the indicated antibody and bound protein was digested with proteinase K. qPCR was performed using SYBR Premix Ex Taq (Takara, Dalian, China). The sequences of the primers used to amplify the ChIP samples are provided in Table I.

Western blot analysis. Total cell protein lysates were prepared using a modified radio-immunoprecipitation assay (RIPA) buffer (50 mM Tris-HCl pH 7.4, $150 \mathrm{mM} \mathrm{NaCl}, 1 \% \mathrm{NP}-40$, $0.25 \%$ sodium deoxycholate and $0.5 \%$ sodium dodecyl sulfate) in the presence of a proteinase inhibitor cocktail (Roche, 
Table I. List of siRNAs, primers and miRNAs utilized in the experiments and their sequences.

\begin{tabular}{|c|c|c|}
\hline Primer name & Application & Sequence \\
\hline Negative control-F & siRNA & UGAAUUAGAUGGCGAUGUUTT \\
\hline Negative control-R & siRNA & AACAUCGCCAUCUAAUUCATT \\
\hline ATF2-F & siRNA & GUUGGCGAGUCCAUUUGAGTT \\
\hline ATF2-R & siRNA & CUCAAAUGGACUCGCCAACTT \\
\hline ELK1-F & siRNA & GGUGAGCGGCCAGAAGUUCTT \\
\hline ELK1-R & siRNA & GAACUUCUGGCCGCUCACCTT \\
\hline YY1-F & siRNA & GGGAGCAGAAGCAGGUGCAGAUTT \\
\hline YY1-R & siRNA & AUCUGCACCUGCUUCUGCUCCCTT \\
\hline XIAP-F & siRNA & GGACAUAGUUUGAAGGUGATT \\
\hline XIAP-R & siRNA & UCACCUUCAAACUAUGUCCTT \\
\hline miR-320a-guide & mimics & AAAAGCUGGGUUGAGAGGGCGAA \\
\hline miR-320a-passenger & mimics & CGCCCUCUCAACCCAGCUUUUUU \\
\hline miR-320a inhibitor & 2' Ome & CCUCUCAACCCAGCUUUU \\
\hline microRNA inhibitor N.C & 2' Ome & CAGUACUUUUGUGUAGUACAA \\
\hline miRNA RT primer & RT & GCGAGCACAGAATTAATACGACTCACTATAGG(T)18VN \\
\hline mRNA RT primer & RT & TTTTTTTTTTTTTTTTTT \\
\hline Universal primer & Real-time PCR & GCGAGCACAGAATTAATACGAC \\
\hline miRNA-320a & Real-time PCR & AAAAGCTGGGTTGAGAGGGCGA \\
\hline U6 snRNA-F & Real-time PCR & CTCGCTTCGGCAGCACA \\
\hline U6 snRNA-R & Real-time PCR & AACGCTTCACGAATTTGCGT \\
\hline GAPDH-F & Real-time PCR & TCAGTGGTGGACCTGACCTG \\
\hline GAPDH-R & Real-time PCR & TGCTGTAGCCAAATTCGTTG \\
\hline pri-miR-320a-F & Real-time PCR & TGAGGTGACTGGTCTGGGCTAC \\
\hline pri-miR-320a-R & Real-time PCR & TCACATTGCGGCGTGGTG \\
\hline XIAP-F & Real-time PCR & GGGGTTCAGTTTCAAGGACA \\
\hline XIAP-R & Real-time PCR & CGCCTTAGCTGCTCTTCAGT \\
\hline ATF2-F & Real-time PCR & CTCCAGCTCACACAACTCCA \\
\hline ATF2-R & Real-time PCR & TGTTTCAGCTGTGCCACTTC \\
\hline ELK1-F & Real-time PCR & CCACCTTCACCATCCAGTCT \\
\hline ELK1-R & Real-time PCR & TCTTCCGATTTCAGGTTTGG \\
\hline YY1-F & Real-time PCR & GGAGGAATACCTGGCATTGA \\
\hline YY1-R & Real-time PCR & TTCTGCACAGACGTGGACTC \\
\hline ChIP-miR-320a-F & Real-time PCR & ACCAGCCGCCAGCCTTCGGTCTCC \\
\hline ChIP-miR-320a-R & Real-time PCR & GCCCAGTCCCGCCCCCCTAACGTC \\
\hline ChIP-GAPDH-F & Real-time PCR & TGATGACATCAAGAAGGTGGTGAAG \\
\hline ChIP-GAPDH-R & Real-time PCR & TCCTTGGAGGCCATGTGGGCCAT \\
\hline 5' RACE RT Primer & 5' RACE & TCACATTGCGGCGTGGTG \\
\hline 5' RACE Primer & 5' RACE & CGACTGGAGCACGAGGACACTGA \\
\hline 5' RACE Nested Primer & 5' RACE & GGACACTGACATGGACTGAAGGAGTA \\
\hline XIAP-1-UTR-F & Cloning & agttctagaTTGAATGTGTGATGTGAACTG \\
\hline XIAP-1-UTR-R & Cloning & agtcatatgAACTAGCAAGGATTAAGGATG \\
\hline XIAP-1-UTR-M-F & Cloning & GCAAAАCTACTTATCACTCTGGTATAGTTTTTCTAАTCCAAGAAG \\
\hline XIAP-1-UTR-M-R & Cloning & CTTCTTGGATTAGAAAAACTATACCAGAGTGATAAGTAGTTTTGC \\
\hline XIAP-2-UTR-F & Cloning & agttctagaTTTTTGGTGCCAATGTGAAA \\
\hline XIAP-2-UTR-R & Cloning & agtcatatgAAGGCGAGTGGATCTCTTGA \\
\hline XIAP-2-UTR-M-F & Cloning & CACTGCTTGTAGTTATAGTGACTGGTATCCATGTTGAGATTCTCATATC \\
\hline XIAP-2-UTR-M-R & Cloning & GATATGAGAATCTCAACATGGATACCAGTCACTATAACTACAAGCAGTG \\
\hline XIAP-3-UTR-F & Cloning & agttctagaTGCTGTTGCTTCAGGTTCTTA \\
\hline XIAP-3-UTR-R & Cloning & agtcatatgAGCCCCATTTTATTTCATTTC \\
\hline XIAP-3-UTR-M-F & Cloning & CCAGTTAATTAATTAATACCATAATATTGCCTTTCСTGCTAC \\
\hline XIAP-3-UTR-M-R & Cloning & GTAGCAGGAAAGGCAATATTATGGTATTAATTAATTAACTGG \\
\hline pCMV6-ATF2-F & Cloning & agtggcgcgccaATGAAATTCAAGTTACATGTG \\
\hline
\end{tabular}


Table I. Continued.

\begin{tabular}{lcl}
\hline Primer name & Application & Sequence \\
\hline pCMV6-ATF2-R & Cloning & agtctcgagAGGTTTTTAATCAACTTCCT \\
pCMV6-ELK1-F & Cloning & agtggcgcgccaATGGACCCATCTGTGACGCTG \\
pCMV6-ELK1-R & Cloning & agtctgagGGTGGTGGTGGTGGTGGTAGTA \\
pCMV6-YY1-F & Cloning & agtggcgcgccaATGGCCTCGGGCGACACCCT \\
pCMV6-YY1-R & Cloning & agtctgagTCACTGGTTGTTTTGGCCTTAGCATGT \\
1,000 bp Fragment-F & Cloning & agtctcgagGGAGAGGCCACAGAGCCTCG \\
1,000 bp Fragment-R & Cloning & agtagcttGCCGCCTGATAAATACTGTGG \\
500 bp Fragment-F & Cloning & agtctcgagGCCGGCCGCCGCCCGATGAG \\
500 bp Fragment-R & Cloning & agtagcttGCCGCCTGATAAATACTGTGG \\
200 bp Fragment-F & Cloning & agtctcgagCAGGAACCAGACAGGGACG \\
200 bp Fragment-R & Cloning & agtagcttGCCGCCTGATAAATACTGTGG \\
$\Delta 200$ Fragment-F & Cloning & agtctcgagGGAGAGGCCACAGAGCCTCG \\
$\Delta 200$ Fragment-R & Cloning & agtagcttGGCGGGGTTCCTGGAGAGG \\
mut-200-ATF2-F & Cloning & CTTGGCGCGGGGCGGAAGAAGCGTTAGGGGGGCGGGAC \\
mut-200-ATF2-R & Cloning & GTCCCGCCCCCTAACGCTTCTTCCGCCCCGCGCCAAG \\
mut-200-ELK1-F & Cloning & TCGGTCTCCGCGCCGGGCTTCAGTCTGCGTGGCAGGGCC \\
mut-200-ELK1-R & Cloning & GGCCCTGCCACGCAGACTGAAGCCCGGCGCGGAGACCGA \\
mut-200-YY1-F & Cloning & GGCAGGGCCTGGGCGCCGTTCTCTTGGCGCGGGGCGGAA \\
mut-200-YY1-F & Cloning & TTCCGCCCCGCGCCAAGAGAACGGCGCCCAGGCCCTGCC \\
\hline
\end{tabular}

The underlined nucleotides in the primer sequences indicate restriction sites (F, forward; $\mathrm{R}$, reverse).

Basel, Switzerland). Protein concentrations were determined using BCA protein assay reagent (Beyotime, Shanghai, China). Protein samples (30 $\mu$ g per lane) were separated by $10 \%$ sodium dodecyl sulfate-polyacrylamide gel electrophoresis (SDS-PAGE) and transferred onto Immobilon Hybond-C membranes (Amersham Biosciences, Piscataway, NJ, USA). After blocking with $5 \%$ non-fat dried milk for $3 \mathrm{~h}$ at room temperature, the membranes were incubated overnight at $4^{\circ} \mathrm{C}$ with primary antibodies. The antibodies used were as follows: ATF2 (1:1,000; ab32160), ELK1 (1:1,000; ab32106), YY1 (1:1,000; ab109237) (all from Abcam), XIAP (1:1,000; 2045), p-ATF2 (1:1,000; 9225), JNK (1:1,000; 9258), p-ELK1 (1:1,000; 9181), p-JNK (1:1,000; 4668), p38 (1:1,000; 9212), p-p38 (1:1,000; 4511), ERK (1:1,000; 4695), p-ERK (1:1,000; 4370) (all from Cell Signaling Technology) and $\beta$-actin (1:1,000; sc-47778; Santa Cruz Biotechnology). The blots were then incubated with horseradish peroxidase-conjugated secondary antibodies (1:3,000; ZB2301; Zhongshan Jinqiao, Beijing, China). Signals were detected with the ECL western blot detection reagent (Thermo Fisher Scientific).

Cell proliferation assays. The HeLa cells were seeded in 60 -mm flasks at $1 \times 10^{5}$ cells, simultaneously transfected with a serial of RNA duplex and incubated at $37^{\circ} \mathrm{C}$ for a further $24 \mathrm{~h}$. The cells were then treated with 8 Gy IR and incubated at $37^{\circ} \mathrm{C}$ for $24 \mathrm{~h}$. The number of living cells was directly counted using the trypan blue exclusion method during the period of 5 days. Briefly, the cells were harvested and resuspended in $1 \mathrm{ml}$ PBS. Subsequently, 1 part cell susupension was mixed with 1 part of $0.4 \%$ trypan blue (Beyotime). The mixture was incubated 3 min at room temperature and counted using a hemacytometer.
Luciferase reporter assays. The HeLa cells were co-transfected with $100 \mathrm{ng}$. Firefly luciferase reporter vector containing plasmid constructs and $1 \mathrm{ng}$ of a control vector containing Renilla luciferase pRL-TK (Promega) in a final volume of $0.5 \mathrm{ml}$ RPMI-1640 in 24-well plates using jetPRIME. The Firefly and Renilla luciferase activities were measured consecutively using a dual-luciferase reporter assay system (Promega) at $48 \mathrm{~h}$ following transfection.

Annexin $V$ apoptosis assays. Annexin V apoptosis assays were performed using an Annexin V-EGFP kit (Biolegend, San Diego, CA, USA) according to the manufacturer's instructions. The stained cells were immediately analyzed on a FACSCalibur flow cytometer (BD Biosciences, Franklin Lakes, NJ, USA). Each measurement was carried out at least in triplicate. The data were displayed as the percentage of apoptotic cells.

Cell proliferation assays and colony forming unit assays. The cell proliferation rate was determined using cell growth curve analysis. Cells were seeded in $60 \mathrm{~mm}$ flasks with $1 \times 10^{5}$ cells, simultaneously transfected with a serial of RNA duplex and incubated for a further $24 \mathrm{~h}$. The cells were then treated with $8 \mathrm{~Gy}$ IR and incubated at $37^{\circ} \mathrm{C}$ for $24 \mathrm{~h}$. The number of living cells was directly counted using the trypan blue exclusion method during the period of 5 days.

For colony forming unit (CFU) assays, the cells were transfected with miR-320a mimics, and 900 cells were seeded in each well of a fresh 6 -well plate for $24 \mathrm{~h}$ prior to transfection. The CFU assay was performed 7 days after transfection, and the scoring criteria for colonies required at least 50 cells per colony. 
A

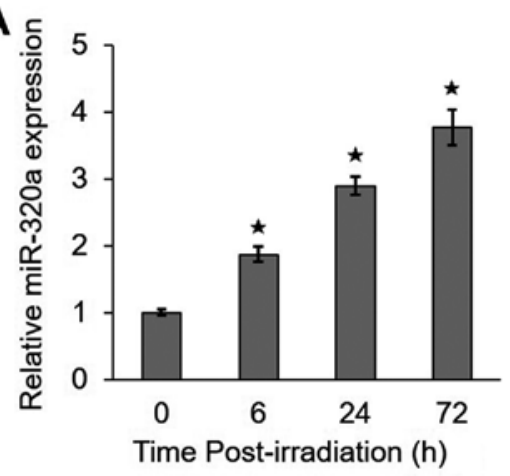

C

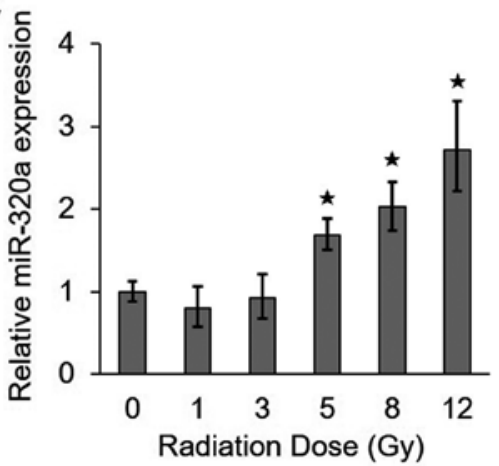

E

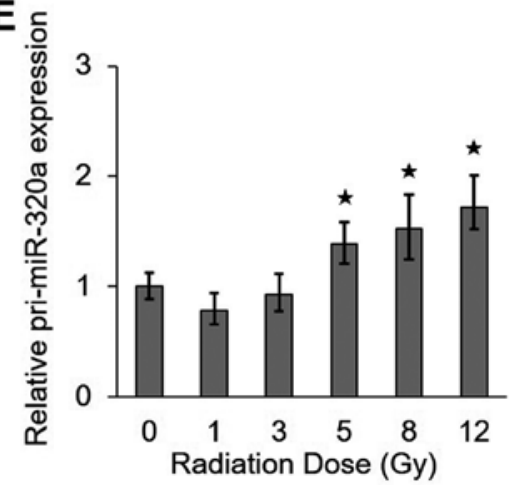

B

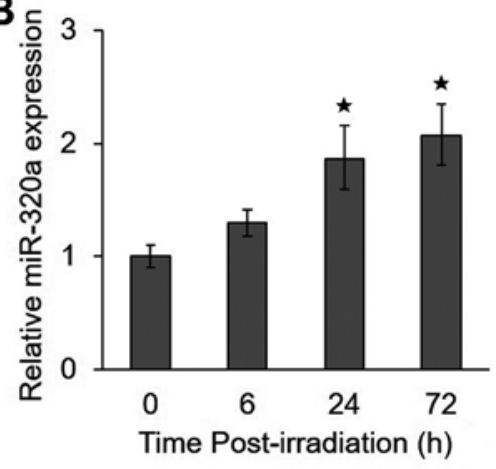

D

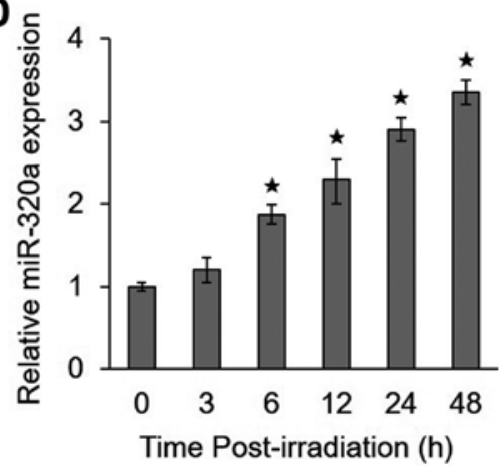

F

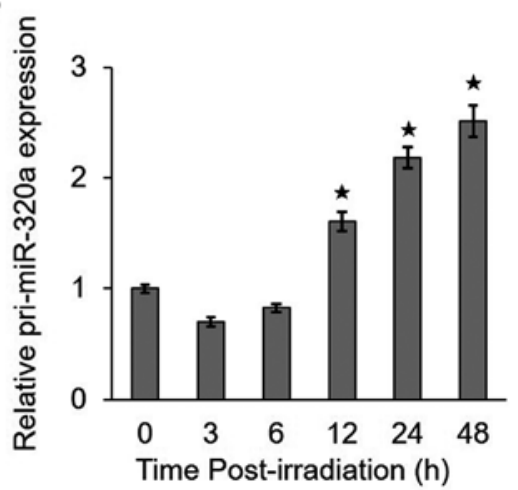

Figure 1. miR-320a expression is induced by ionizing radiation. (A and B) Response of miR-320a to radiation with 8 Gy IR in (A) HeLa and (B) HCT116 cells. U6 snRNA was used for normalization. ${ }^{*} \mathrm{P}<0.05$. (C and D) Response of miR-320a to radiation doses (C) at $24 \mathrm{~h}$ following exposure to IR and (D) radiation time with 8 Gy IR in HeLa cells. U6 snRNA was used for normalization. ${ }^{*} \mathrm{P}<0.05$. (E and F) Response of pri-miR-320a to (E) radiation doses at 24 h following exposure to IR and (F) radiation time with $8 \mathrm{~Gy}$ IR in HeLa cells. GAPDH was used for normalization. "P $<0.05$. IR, ionizing radiation.

Statistical analysis of the data. Unless otherwise indicated, all the values are reported as the means \pm standard deviation. Data analyses were estimated using SPSS software version 18.0 (IBM SPSS, Armonk, NY, USA). When the datasets contained multiple groups, statistical differences were evaluated by a one-way ANOVA with Dunnett's post hoc test. When only 2 groups were compared once in the datasets, statistical differences were evaluated using a Student's t-test. A value of $\mathrm{P}<0.05$ was considered to indicate a statistically significant difference.

\section{Results}

IR upregulates miR-320a expression. To identify which miRNAs are regulated by IR, we performed a miRNA microarray analysis in HeLa cells treated with 8 Gy IR. We previously found that the upregulation of miR-320a expression by IR was significant using a strict cut-off value of $\mathrm{P}<0.01$ ( $>2.7$-fold) (17). To confirm the microarray results, we analyzed miR-320a expression by RT-qPCR in the HeLa and HCT-116 cells under IR conditions. We found that the expression of miR-320a increased with time from 0 to $72 \mathrm{~h}$ in the HeLa cells (Fig. 1A) and HCT116 cells (Fig. 1B) treated with $8 \mathrm{~Gy}$ IR. In addition, the expression of miR-320a also increased with radiation doses ranging from 1 to $12 \mathrm{~Gy}$ at $24 \mathrm{~h}$ following exposure to IR (Fig. 1C) and with the radiation time ranging from 0 to $48 \mathrm{~h}$ following exposure to 8 Gy IR (Fig. 1D) in the HeLa cells. To determine whether miR-320a accumulation is mediated by transcriptional regulation, we also detected the expression of the primary precursor of miR-320a (pri-miR-320a). Of note, we found that pri-miR-320a exhibited similar expression profiles as miR-320a (Fig. 1E and F). Taken together, these data suggested that miR-320a was highly responsive to treatment with IR.

ATF2, ELK1 and YY1 interact directly with miR-320a promoter. To elucidate the mechanisms through which miR-320a is 

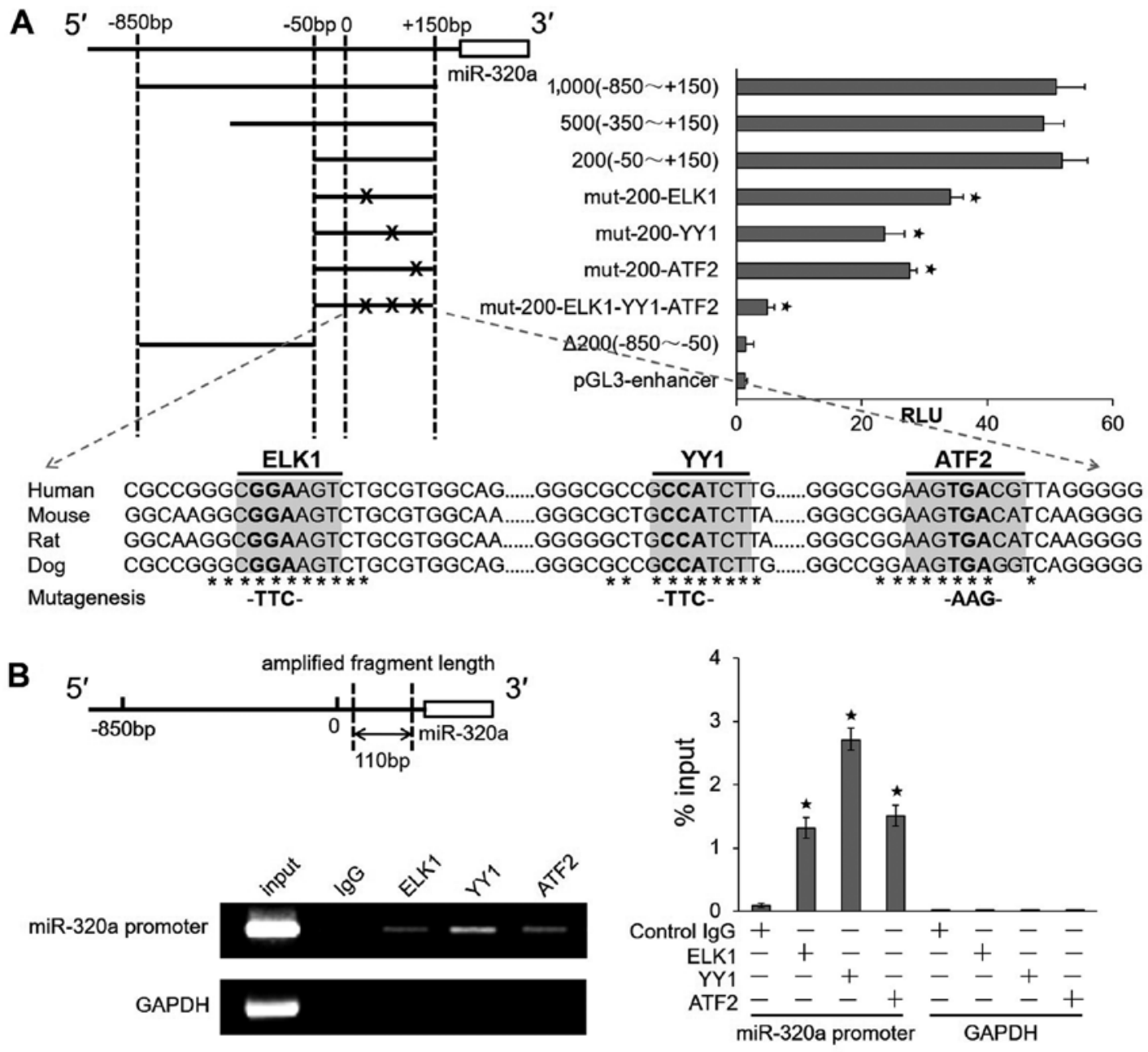

C

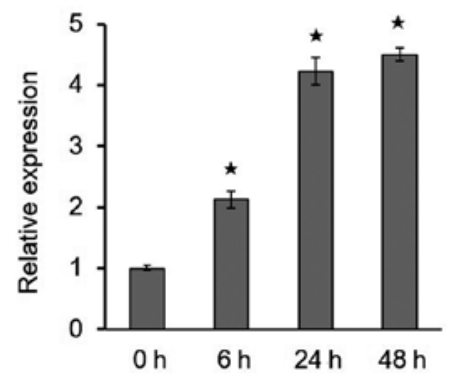

E

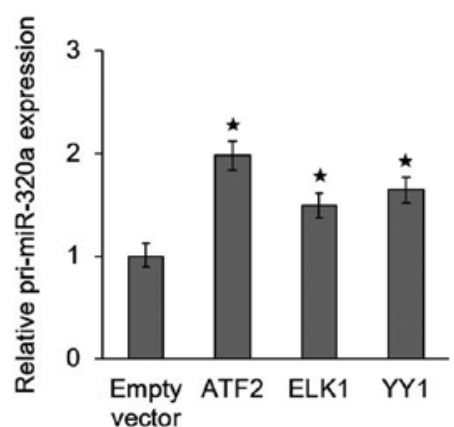

D

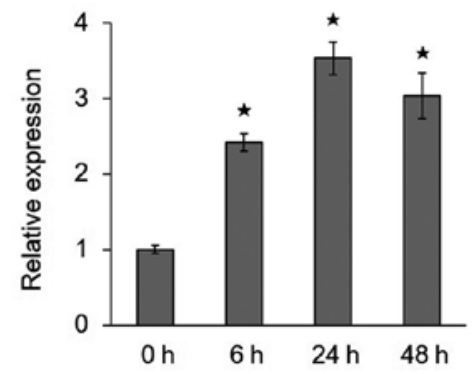

$\mathbf{F}$

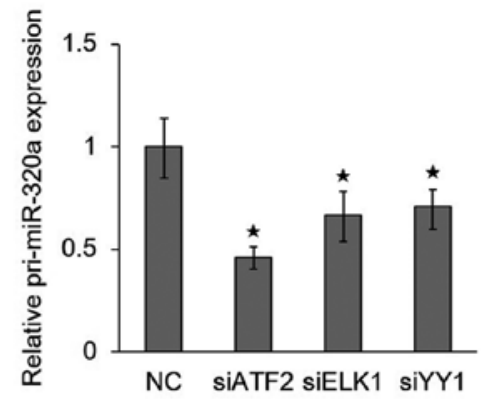

Figure 2. Characterization of miR-320a promoter. (A) A schematic view of miR-320a promoter constructs (top left panel). Open box indicates the coding region of miR-320a and solid lines indicate the $1 \mathrm{~kb}$, and 500,200 and $\Delta 200 \mathrm{bp}$ promoter fragments. The ' $\mathrm{x}$ ' symbols in the solid lines represent the mutations of three binding sites by transcription factors on the miR-320a promoter sequence. The relative luciferase units (RLU) of activities are shown on the top right panel; ${ }^{*} \mathrm{P}<0.05$. The conservation of miR-320a genomic sequences are indicated by asterisks $\left(^{*}\right)$ across species (bottom panel). 'Mutagenesis' indicates mutations in the core of the binding sites in bold letters. (B) ChIP analysis of the miR-320a promoter. The relative locations of ChIP primers on the miR-320a promoter are shown (top left panel). Semi-quantitative PCR was performed with primers specific to the binding sites and DNA sequence of the GAPDH coding region was served as a control (bottom left panel). RT-qPCR analysis was used to assess the level of the miR-320a promoter DNA sequence (right panel). ${ }^{*}<0.05$. (C and D) ChIP analysis of the miR-320a promoter in response to the radiation time following treatment with 8 Gy IR in (C) HeLa and (D) HCT116 cells. ${ }^{*} \mathrm{P}<0.05$. (E and F) The expression of pri-miR-320a was analyzed by RT-qPCR with following transfection with (E) overexpression vector or (F) siRNAs against $A T F 2, E L K 1$ and $Y Y 1(\mathrm{~F})$ in HeLa cells. GAPDH was used for normalization. ${ }^{*} \mathrm{P}<0.05$. IR, ionizing radiation. 
A

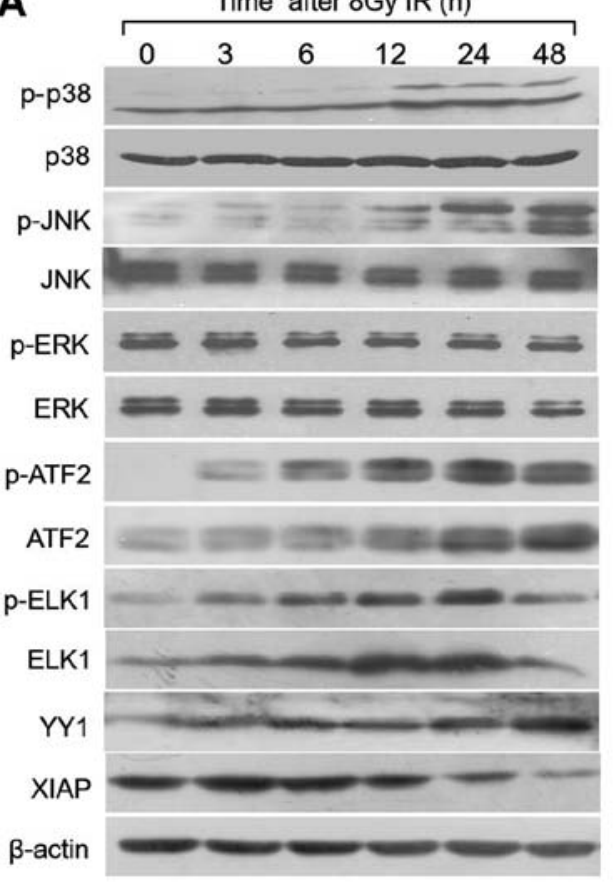

B
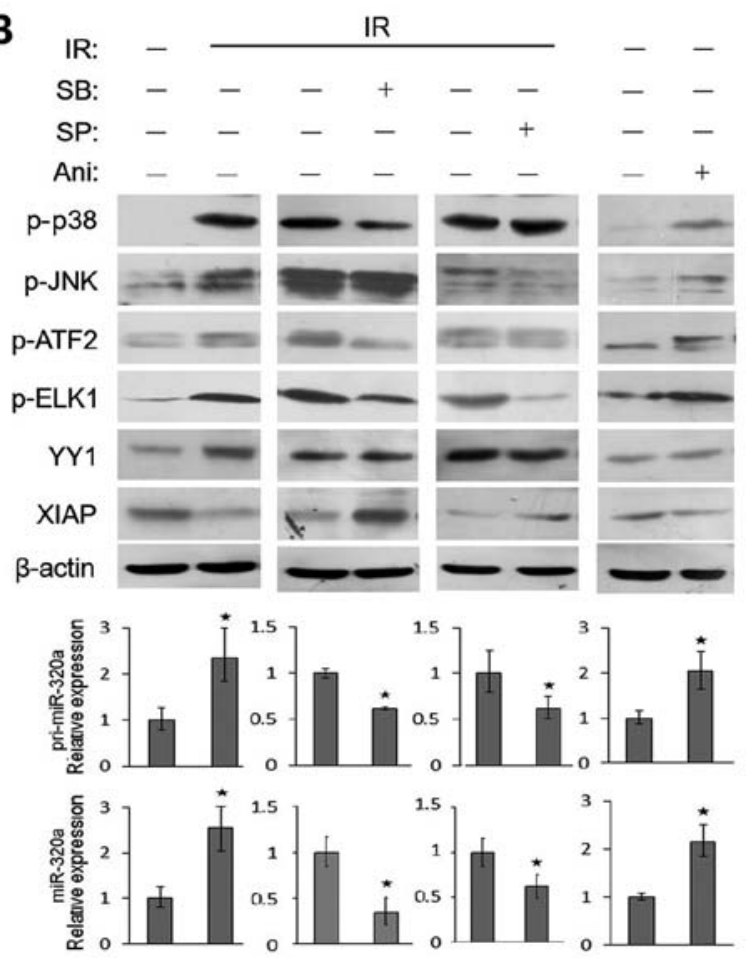

Figure 3. p38 MAPK and JNK activate transcription factors that regulate miR-320a expression following IR. (A) Effects of 8 Gy IR on the total protein or phosphorylation levels in HeLa cells. $\beta$-actin was used as a loading control. (B) Altered activation of p38 or JNK regulated the activation of ATF2 and ELK1, inducing the expression of pri-miR-320a and miR-320a. $\beta$-actin was used as a loading control. U6 snRNA and GAPDH were respectively used for normalization. "P<0.05. p-ATF2, phospho-ATF2; p-JNK, phospho-JNK; p-p38, phospho-p38; p-ELK1, phsopho-ELK1; SB, SB203580 (p38 inhibitor); SP, SP600125 (JNK inhibitor); Ani, anisomycin (p38 and JNK agonist); IR, ionizing radiation.

upregulated by IR, we examined the precise location of the miR-320a promoter region. Four serial deletion luciferase reporter gene vectors $(1,000,800,500$ and $200 \mathrm{bp}$ fragments) were constructed (Fig. 2A, top left panel), and their relative luciferase reporter units were measured. We observed that a $200 \mathrm{bp}$ fragment was responsible for the robust induction of the miR-320a promoter. The analysis of the $200 \mathrm{bp}$ miR-320a core-promoter sequence using the TFSEARCH program (http://diyhpl. us/ bryan/irc/protocol-online/protocol-cache/TFSEARCH.html) suggested that there were three potential transcription factor binding sites for ATF2, ELK1 and YY1. The mutation of any of these three binding sites could attenuate luciferase activities, and the simultaneous mutation of all three sites completely abolished the responsiveness of the promoter to these transcription factors (Fig. 2A, top right panel). Moreover, these three sites were highly conserved in the human, mouse, rat and dog miR-320a genomic sequences (Fig. 2A, bottom panel), implying that these elements were functionally important.

To determine whether these transcription factors directly bind the miR-320a promoter, we performed ChIP assays using anti-ATF2, anti-ELK1 and anti-YY1 antibodies. The results revealed that the miR-320a promoter sequences were enriched in these samples compared to the samples precipitated with an isotype-matched normal IgG. Moreover, an irrelevant DNA sequence (GAPDH coding region) was not specifically precipitated by these antibodies (Fig. 2B, top left panel). The ChIP results were also confirmed by RT-qPCR (Fig. 2B, bottom left and right panel). Moreover, we performed the ChIP assay using anti-ATF2 with a radiation time ranging from 0 to $48 \mathrm{~h}$ in HeLa cells (Fig. 2C) and HCT116 cells (Fig. 2D) treated with 8 Gy IR. The results indicated that the miR-320a promoter sequences were enriched by ATF2. Furthermore, the overexpression of ATF2, ELK1 and YY1 in HeLa cells could lead to the upregulation of pri-miR-320a expression (Fig. 2E). By contrast, the knockdown of ATF2, ELK1 and YY1 significantly suppressed the expression of pri-miR-320a (Fig. 2F). We obtained similar results in the HCT116 cells (data not shown). Taken together, these results suggest that ATF2, ELK1 and $Y Y 1$ can bind the miR-320a promoter and promote the transcription of miR-320a under IR conditions.

p38 MAPK and JNK activate transcription factors to regulate miR-320a expression under IR conditions. Both the p38 MAPK and JNK signaling pathways play a vital role in cellular response to IR, UV light and oxygen stress $(24,25)$. ATF 2 and ELK1 can be both phosphorylated by p38 and JNK. In order to identify whether these signal transduction pathways stimulate miR-320a expression under IR conditions, we first examined the phosphorylation and activity of these two signal transduction pathways in response to IR in HeLa cells. As shown in Fig. 3A, the levels of phosphorylated p38 (p-p38) and phosphorylated JNK (p-JNK) were found to gradually increase from 3 to $48 \mathrm{~h}$ following treatment with 8 Gy IR, with a peak expression at $48 \mathrm{~h}$; the total protein levels of p38 and JNK were not altered. By contrast, IR did not alter the phosphorylation or expression levels of endogenous ERK protein. As targets of p38 and JNK, the phosphorylation or expression levels of ATF2 and ELK1 were also activated (Fig. 3A); similar results were obtained with the HCT116 cells (data not shown). Moreover, these expression profiles were consistent with those of miR-320a expression (Fig. 1D). 

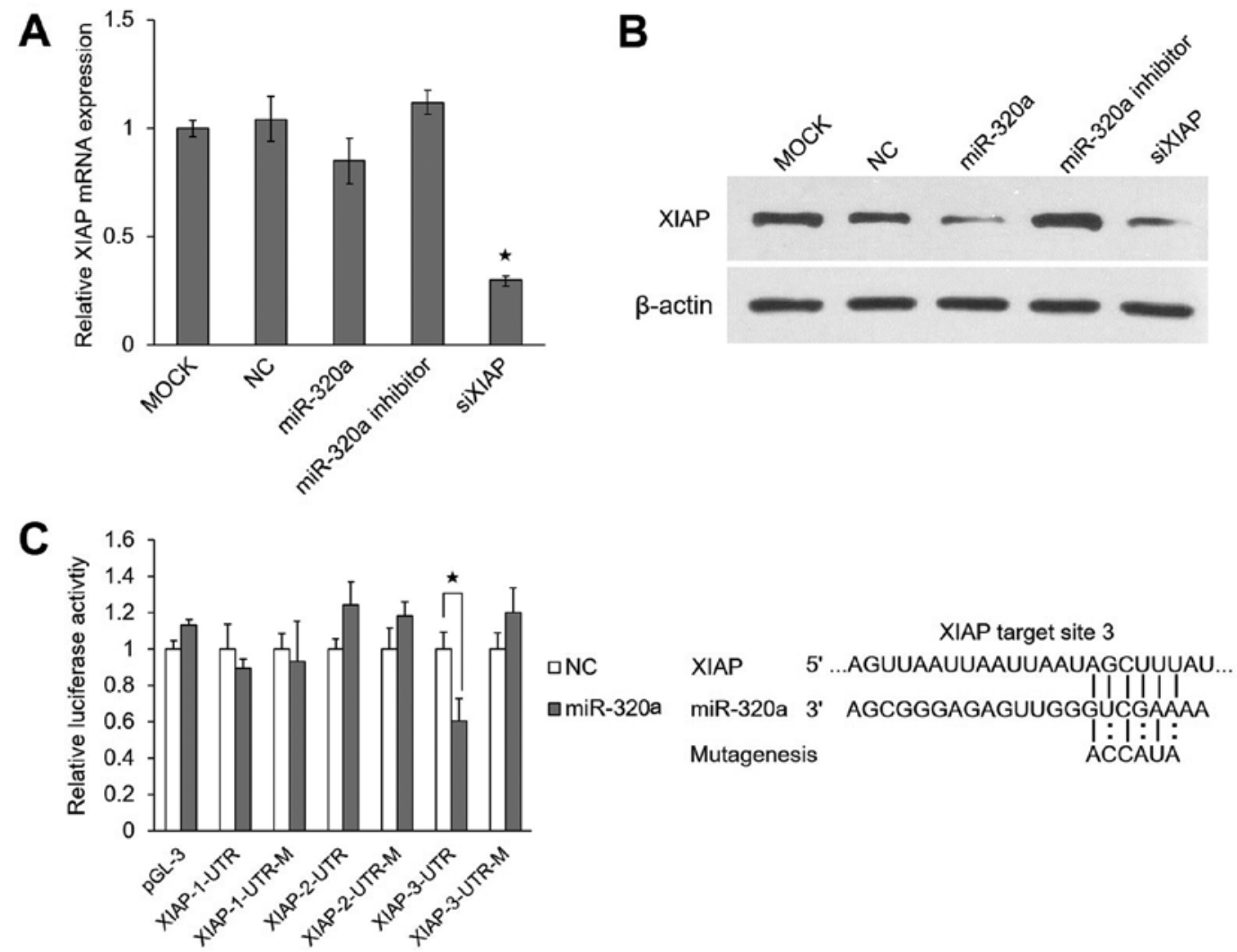

Figure 4. XIAP is directly targeted by miR-320a. (A) The overexpression or the inhibition of miR-320a had little effect on the mRNA level of XIAP in HeLa cells. GAPDH was used for normalization. " $\mathrm{P}<0.05$. (B) The overexpression or the inhibition of miR-320a can affect the protein level of XIAP in HeLa cells. $\beta$-actin was used as a loading control. (C) miR-320a targeted the 3'UTR of XIAP. ${ }^{*} \mathrm{P}<0.05$.

To investigate whether the regulation of miR-320a expression by ATF2, YY1 and ELK1 is mediated by p38 and JNK, we detected their expression levels in HeLa cells treated with two specific chemical inhibitors of p38 (SB203580) and JNK (SP600125) or an agonist of p38 and JNK (anisomycin). The results revealed that either anisomycin or IR directly increased the protein expression or phosphorylation of a series of proteins, including p38, JNK, ATF2, ELK1 and YY1 (Fig. 3B, top panels). Moreover, the transcription of pri-miR-320a and miR-320a expression also increased (Fig. 3B, bottom panels). SB203580 or SP600125 inhibited the phosphorylation of ATF2 and ELK1, but not that of YY1 (Fig. 3B, top panels), resulting in the decreased expression of pri-miR-320a and miR-320a (Fig. 3B, bottom panels). The results suggested that IR induces the expression of YY1 and the phosphorylation of ATF2 and ELK to induce miR-320a expression through the p38 MAPK/JNK pathway.

miR-320a suppresses XIAP expression by targeting its $3^{\prime} U T R$. miRNAs can regulate their target genes by inhibiting protein translation and/or degrading mRNAs. In this study, we found that the 3'UTR of XIAP had 3 predicted target sites, through TargetScan (http://www.targetscan.org/) (26). XIAP protein is necessary for anti-apoptotic function and is usually overexpressed in cancer cells $(27,28)$.

In this study, we found that the overexpression or the inhibition of miR-320a had little effect on the mRNA level of XIAP in HeLa cells (Fig. 4A), but markedly affected its protein level (Fig. 4B). These results support the hypothesis that miR-320a regulates the expression of XIAP directly at the translational level.

To determine whether miR-320a targets the 3'UTR of the $X I A P$ gene directly, luciferase reporter assays were performed using the HeLa cells. The results revealed that miR-320a significantly decreased the relative luciferase activity $(\sim 42 \%)$ of XIAP-3-3'UTR as compared to the negative control. However, the reporter with mutated effective target was not suppressed by miR-320a (Fig. 4C). These results indicated that $X I A P$ was indeed a direct target of miR-320a.

miR-320a enhances cellular radiosensitivity by inducing apoptosis and suppressing proliferation. To validate whether miR-320a induces apoptosis, we performed an Annexin V apoptosis assay using the HeLa cells. The results revealed that approximately $14.79 \%$ of HeLa cells transfected with miR-320a underwent apoptosis compared with 5.94\% of untreated (mock) cells and $5.79 \%$ of the control cells. Similarly, $16.82 \%$ of the cells transfected with XIAP siRNA underwent apoptosis, suggesting that miR-320a promotes apoptosis by regulating XIAP expression (Fig. 5A).

IR can cause multiple types of cellular responses, such as DNA strand breaks, cell cycle arrest and apoptosis (29). Radiotherapy is an important treatment for cancer patients, and miR-320a expression can be induced by IR. This led us to examine whether miR-320a can affect the proliferation of tumor cells. We used the trypan blue exclusion method to evaluate the proliferation of HeLa cells overexpressing miR-320a. We observed that miR-320a inhibited cell proliferation compared 
A

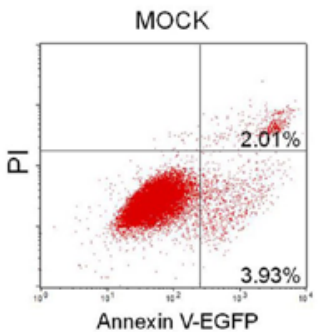

$\operatorname{miR}-320 a$

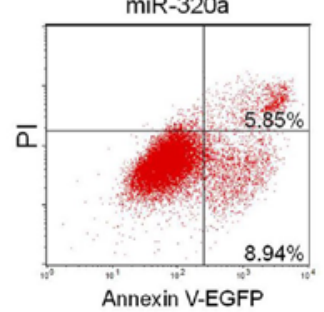

Annexin V-EGFP

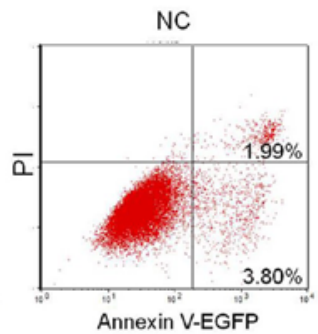

SiXIAP

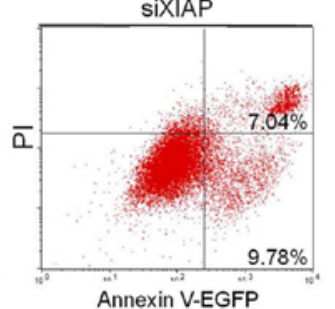

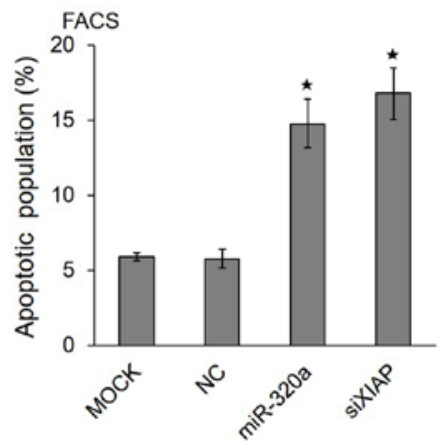

B

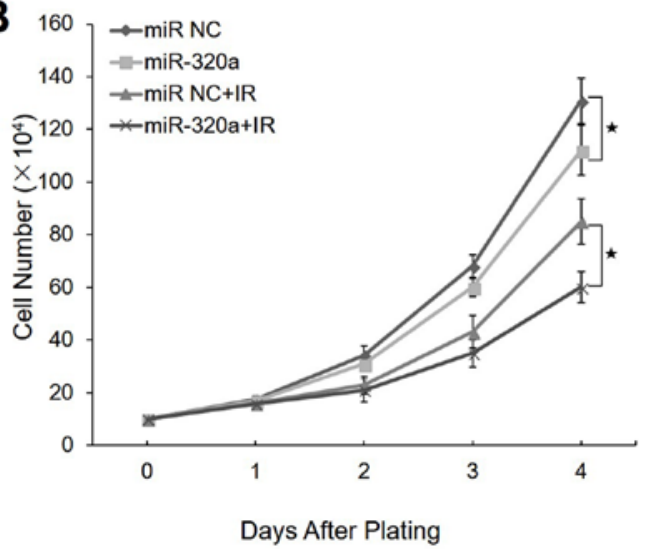

D

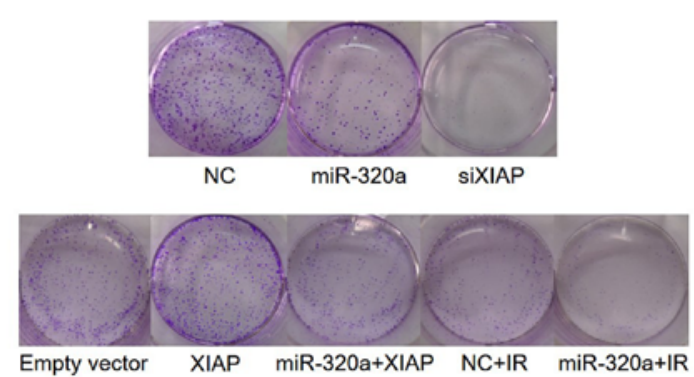

C
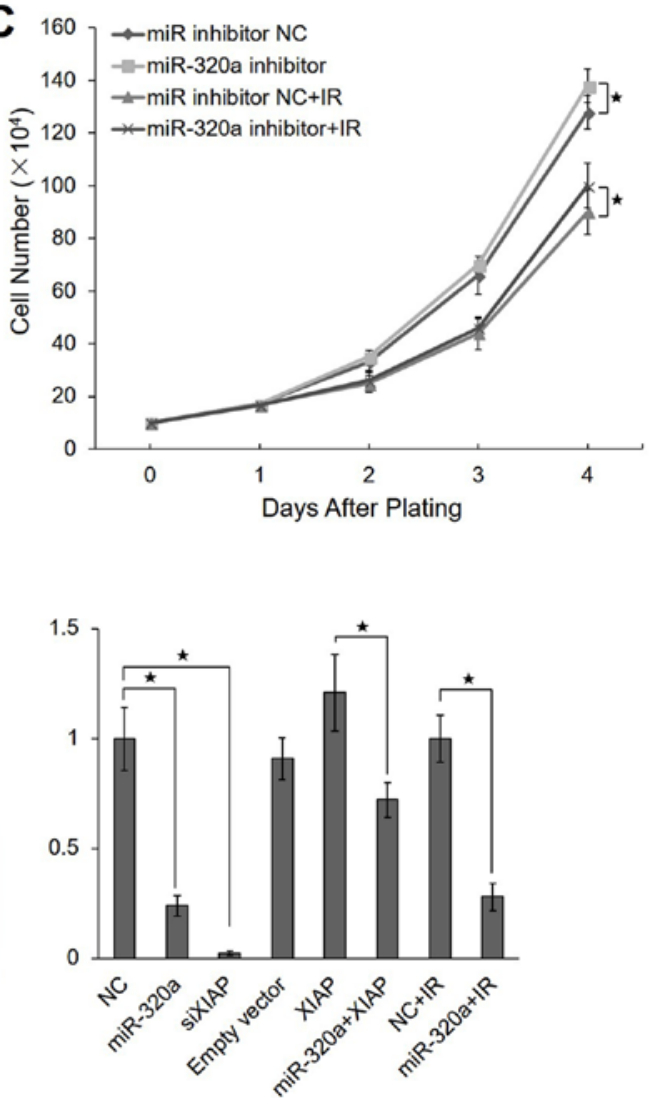

Figure 5. miR-320a induces the apoptosis and suppresses proliferation under IR conditions. (A) miR-320a induces the apoptosis of HeLa cells. Apoptosis was assessed by FACS analysis. ${ }^{*} \mathrm{P}<0.05$. (B) The overexpression of miR-320a inhibited the growth of HeLa cells following treatment with $8 \mathrm{~Gy}$ IR. ${ }^{*} \mathrm{P}<0.05$. (C) The inhibition of miR-320a slightly increased the growth if HeLa cells following treatment with 8 Gy IR. *P<0.05. (D) miR-320a suppresses the colony formation of HeLa cells following treatment with 8 Gy IR. * $\mathrm{P}<0.05$. IR, ionizing radiation.

with the negative control (Fig. 5B). In IR-treated HeLa cells, miR-320a also inhibited cell proliferation (Fig. 5B). When the miR-320a inhibitor was transfected into HeLa cells simultaneously, the HeLa cells exhibited a partial reversal of IR-induced apoptosis (Fig. 5C).

To determine the potential role of miR-320a in tumorigenesis, the colony formation capacity of the HeLa cells was evaluated following transfection with miR-320a. Notably, the miR-320a-overexpressing group displayed evidently fewer and smaller colonies compared with the control group (Fig. 5D).
These data indicated that miR-320a enhanced radiosensitivity by inducing apoptosis and suppressing proliferation under IR conditions.

Overall, the results of this study suggested that IR induced the phosphorylation of p38 and JNK, and activated their downstream targets-ATF2, ELK1 and YY1, resulting in the transcription of miR-320a, thus increasing the expression of miR-320a to inhibit XIAP, and consequently inducing apoptosis and inhibiting proliferation to realize its biological function (Fig. 6). 


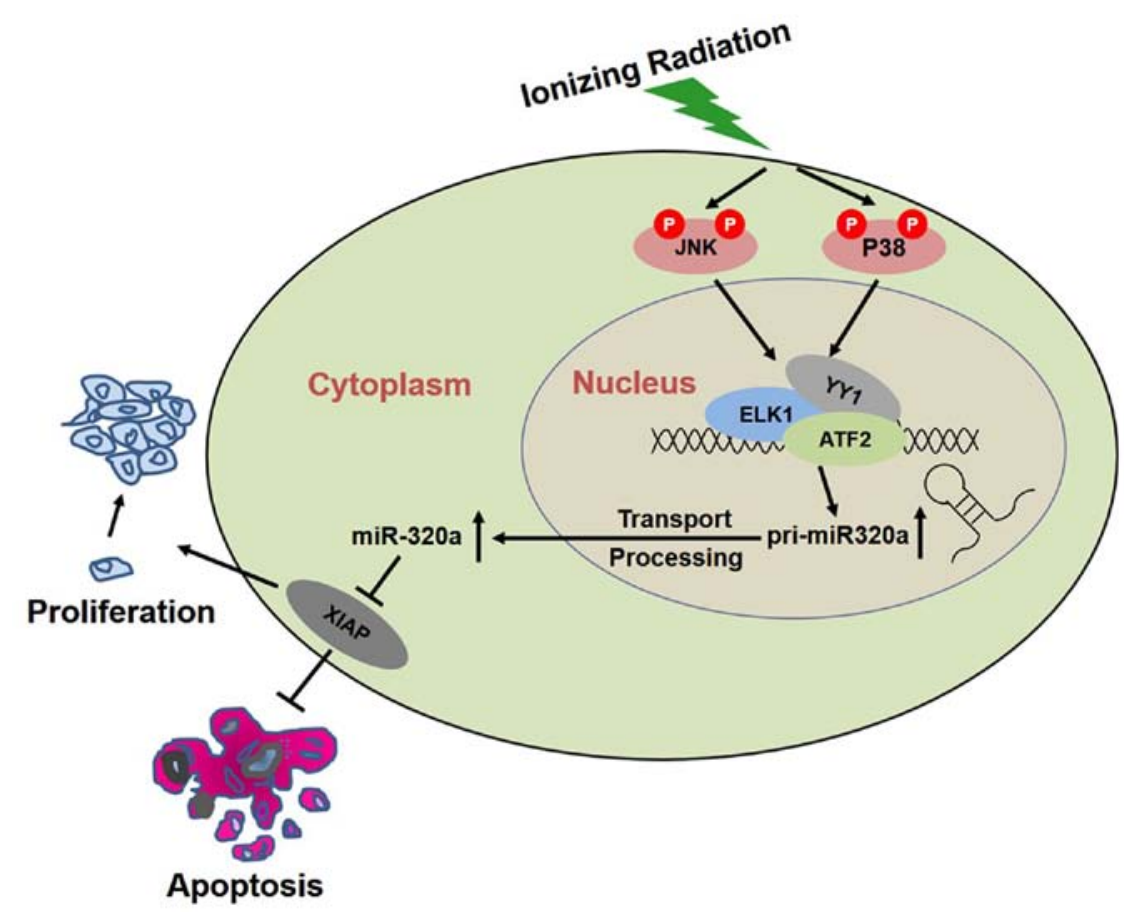

Figure 6. A schematic diagram illustrating that miR-320a carries out its function through the p38 MAPK and JNK pathways under ionizing radiation (IR) conditions. IR induced the phosphorylation of $\mathrm{p} 38$ and JNK, activated their downstream targets, ATF2, ELK1 and YY1, resulting in the transcription of miR-320a, increasing the expression of miR-320a to inhibit XIAP, and consequently inducing apoptosis and inhibiting proliferation to realize its biological function.

\section{Discussion}

Although it has reported that miRNA expression was induced by IR in cancer cells $(4,30,31)$, the expression of the majority of these IR-induced miRNAs was irregular with radiation dose or time. In this study, we observed that miR-320a expression increased in a dose- and time-dependent manner under IR conditions, particularly with high doses or longer treatment periods. It would be of interest to elucidate the mechanisms through which miR-320a is regulated and to examine its target gene in response to IR in cancer cells.

In this study, miR-320a expression, as a potential tumor suppressor, increased linearly with radiation doses or treatment duration under IR conditions. However, the mechanisms underlying the response of miR-320a to IR are unclear. We analyzed the precise location of the miR-320a promoter region and transcriptional start site (TSS). We identified that ATF2, ELK1 and YY1 were activated by the p38 MAPK and JNK pathways under IR conditions and regulated miR-320a expression by binding to its promoter.

ATF2 is a member of the bZIP transcription factor family, which has been implicated in the transcriptional regulation of cytokines, cell cycle control proteins and apoptotic factors (32-34). ATF2 is regulated by p38 MAPK/JNK in response to stress and plays a role in the DNA damage response and ATM phosphorylates ATF2 on Ser490 and Ser498 following exposure to IR $(35,36)$. ELK1 is a component of the ternary complex that binds the serum response element (SRE) in response to serum growth factors (37). ELK1 is phosphorylated by MAPKs [extracellular signal-related kinase (ERK)1 and ERK2], and the Ser383 residue of ELK1 is also a target of several stress-activated kinases (SAPK/JNK1, JNK2 and p38). The expression of ELK1 phosphorylated on
Ser383 in the rat jejunum and transverse colon has been shown to be dependent on doses and time following whole-body $\gamma$-irradiation (38). YY1 is a 414-amino-acid Krüppel-related zinc finger transcription factor and enhancer of many cellular and viral genes. YY1 attenuates p53-dependent transcription in a subset of p53-target genes. Notably, YY1 is associated with cellular proliferation and transformation (39).

In this study, the overexpression or inhibition of ATF2 observably influenced pri-miR-320a expression, suggesting that ATF2 may be the key transcription factor regulating miR-320a. Whether other miRNAs are controlled by ATF2 may be worth studying in the future. Our results suggested that the p38 MAPK and JNK pathways induced miR-320a expression, leading to cell apoptosis under IR conditions. It would be of interest to investigate whether they also regulate miR-320a expression during oncogenesis in the future.

The data of this study identified that XIAP was a novel target gene of miR-320a. XIAP is a member of the inhibitors of apoptosis (IAP) family, which are endogenous inhibitors of caspase-3,-7 and -9 (40). XIAP has been shown to be critical for regulating sensitivity to apoptosis induced by cellular stress and DNA damage (41). The present study revealed that miR-320a enhanced radiosensitivity at least partly by inhibiting XIAP expression. Furthermore, we aimed to examine the association between XIAP and miR-320a in these radiated samples using Spearman's rank correlation analysis. The results revealed that there was not a significant negative correlation $(\mathrm{r}=0.278$, $\mathrm{P}=0.066$ ) (data not shown) between them in the cell samples at $24 \mathrm{~h}$ after 8 Gy IR. The possible reason leading to this result may be as follows: Small cell sample sizes, the complexity of IR and the miR-320a regulatory network.

In this study, our data suggested that the overexpression of miR-320a enhanced the radiosensitivity of HeLa cells by 
inducing cell apoptosis, and inhibiting proliferation or colony formation. We hypothesized that miR-320a was upregulated under IR conditions by the activated MAPK pathway and then regulated its target genes, including XIAP, resulting in cell apoptosis, and reduced proliferation or colony formation (Fig. 6). As shown in Fig. 5A, $14.79 \%$ of HeLa cells transfected with miR-320a underwent apoptosis compared with $5.94 \%$ of untreated cells and $5.79 \%$ of control cells. In general, the apoptotic population is in the range from 10 to $30 \%$ in HeLa cells treated with miRNAs (42-44). In addition, in this study, we observed that miR-320a inhibited the proliferation of either IR-untreated or -treated HeLa cells (Fig. 5B), while miR-320a inhibitor exhibited a partial reversal of IR-induced apoptosis (Fig. 5C), suggesting that miR-320a indeed enhanced radiosensitivity in response to IR. As for that miR-320a inhibitor had a weak effect, this was probably due to the low expression of miR-320a in HeLa cells (data not shown).

In conclusion, this study provides evidence that miR-320a expression increases in a dose- or time-dependent manner under IR conditions and that its transcription is directly regulated by ATF2, YY1 and ELK1. The findings of this study also demonstrated that miR-320a enhanced radiosensitivity by inhibiting its target gene, XIAP. XIAP served as a specific tumor therapeutic target due to its important roles in tumorigenesis. Since miR-320a can regulate multiple target genes to inhibit cell growth, it is possible that the exogenous expression of miR-320a may be a more effective tumor therapy than the depletion of a single oncogene. In this study, we only investigated the role of miR-320a in response to IR in vitro. It would be interesting to reveal whether such a regulation of miR-320a occurs in vivo. In the future, the re-introduction of miR-320a in vivo may be useful as a radiation sensitizer, once miRNA delivery to tumor becomes feasible.

\section{Acknowledgements}

The authors would like to express their sincere gratitude to Dr Lingqiang Zhang, from the Beijing Institute of Radiation Medicine for reading the manuscript and providing and helpful suggestions.

\section{Funding}

This study was supported by Chinese National Natural Science Foundation projects (31370760, 91540202, 31470782 and 81702925 ) and by the Natural Science Foundation of Heilongjiang Province (H201403 and H2018002).

\section{Availability of data and materials}

The datasets used and/or analyzed during the current study are available from the corresponding author on reasonable request.

\section{Authors' contributions}

$\mathrm{HF}$ and $\mathrm{XZ}$ conceived the project and contributed to the study design; ZH, YT, GL and JZ performed data collection; ZH, YT and HF analyzed and interpreted the data; ZH, YT and HF wrote the manuscript; all authors HAVE read and approved the final version of the manuscript.

\section{Ethics approval and consent to participate}

Not applicable.

\section{Patient consent for publication}

Not applicable.

\section{Competing interests}

The authors declare that they have no competing interests.

\section{References}

1. Bartel DP: MicroRNAs: Genomics, biogenesis, mechanism, and function. Cell 116: 281-297, 2004.

2. Huang X, Ding L, Bennewith KL, Tong RT, Welford SM, Ang KK, Story M, Le QT and Giaccia AJ: Hypoxia-inducible mir-210 regulates normoxic gene expression involved in tumor initiation. Mol Cell 35: 856-867, 2009.

3. Leung AK and Sharp PA: MicroRNA functions in stress responses. Mol Cell 40: 205-215, 2010.

4. Simone NL, Soule BP, Ly D, Saleh AD, Savage JE, Degraff W, Cook J, Harris CC, Gius D and Mitchell JB: Ionizing radiationinduced oxidative stress alters miRNA expression. PLoS One 4: e6377, 2009.

5. Wilke CM, Hess J, Klymenko SV, Chumak VV, Zakhartseva LM, Bakhanova EV, Feuchtinger A, Walch AK, Selmansberger M, Braselmann H, et al: Expression of miRNA-26b-5p and its target TRPS1 is associated with radiation exposure in post-Chernobyl breast cancer. Int J Cancer 142: 573-583, 2018.

6. Niemoeller OM, Niyazi M, Corradini S, Zehentmayr F, Li M, Lauber K and Belka C: MicroRNA expression profiles in human cancer cells after ionizing radiation. Radiat Oncol 6: 29, 2011.

7. Yano H, Hamanaka R, Nakamura-Ota M, Zhang JJ, Matsuo N and Yoshioka $\mathrm{H}$ : Regulation of type I collagen expression by microRNA-29 following ionizing radiation. Radiat Environ Biophys 57: 41-54, 2018.

8. Chaudhry MA, Sachdeva $\mathrm{H}$ and Omaruddin RA: Radiationinduced micro-RNA modulation in glioblastoma cells differing in DNA-repair pathways. DNA Cell Biol 29: 553-561, 2010.

9. He L, He X, Lim LP, de Stanchina E, Xuan Z, Liang Y, Xue W, Zender L, Magnus J, Ridzon D, et al: A microRNA component of the p53 tumour suppressor network. Nature 447: 1130-1134, 2007.

10. Kovalchuk O,Zemp FJ, Filkowski JN, Altamirano AM, Dickey JS, Jenkins-Baker G, Marino SA, Brenner DJ, Bonner WM and Sedelnikova OA: microRNAome changes in bystander threedimensional human tissue models suggest priming of apoptotic pathways. Carcinogenesis 31: 1882-1888, 2010.

11. Cha HJ, Seong KM, Bae S, Jung JH, Kim CS, Yang KH, Jin YW and An S: Identification of specific microRNAs responding to low and high dose gamma-irradiation in the human lymphoblast line IM9. Oncol Rep 22: 863-868, 2009.

12. Sokolov M and Neumann R: Global gene expression alterations as a crucial constituent of human cell response to low doses of ionizing radiation exposure. Int J Mol Sci 17: 17, 2015.

13. Begg AC, Stewart FA and Vens C: Strategies to improve radiotherapy with targeted drugs. Nat Rev Cancer 11: 239-253, 2011.

14. Lal A, Pan Y, Navarro F, Dykxhoorn DM, Moreau L, Meire E, Bentwich Z, Lieberman J and Chowdhury D: miR-24-mediated downregulation of H2AX suppresses DNA repair in terminally differentiated blood cells. Nat Struct Mol Biol 16: 492-498, 2009.

15. Mateescu B, Batista L, Cardon M, Gruosso T, de Feraudy Y, Mariani O, Nicolas A, Meyniel JP, Cottu P, Sastre-Garau X, et al: miR-141 and miR-200a act on ovarian tumorigenesis by controlling oxidative stress response. Nat Med 17: 1627-1635, 2011.

16. Adusumilli PS, Chan MK, Hezel M, Yu Z, Stiles BM, Chou TC, Rusch VW and Fong Y: Radiation-induced cellular DNA damage repair response enhances viral gene therapy efficacy in the treatment of malignant pleural mesothelioma. Ann Surg Oncol 14: 258-269, 2007.

17. Hu Z, Tie Y, Lv G, et al: Correlation of microRNAs responding to high dose $\gamma$-irradiation with predicted target mRNAs in HeLa cells using microarray analyses. Chin Sci Bull 58: 4622-4629, 2013. 
18. Diakos C, Zhong S, Xiao Y, Zhou M, Vasconcelos GM, Krapf G, Yeh RF, Zheng S, Kang M, Wiencke JK, et al: TEL-AML1 regulation of survivin and apoptosis via miRNA-494 and miRNA-320a. Blood 116: 4885-4893, 2010

19. Xie F, Yuan Y, Xie L, Ran P, Xiang X, Huang Q, Qi G, Guo X, Xiao $\mathrm{C}$ and Zheng S: miRNA-320a inhibits tumor proliferation and invasion by targeting c-Myc in human hepatocellular carcinoma. OncoTargets Ther 10: 885-894, 2017.

20. Bronisz A, Godlewski J, Wallace JA, Merchant AS, Nowicki MO, Mathsyaraja H, Srinivasan R, Trimboli AJ, Martin CK, Li F, et al: Reprogramming of the tumour microenvironment by stromal PTEN-regulated miR-320. Nat Cell Biol 14: 159-167, 2011.

21. Liu Q, Fu H, Sun F, Zhang H, Tie Y, Zhu J, Xing R, Sun Z and Zheng X: miR-16 family induces cell cycle arrest by regulating multiple cell cycle genes. Nucleic Acids Res 36: 5391-5404, 2008

22. Fu HJ, Zhu J, Yang M, Zhang ZY, Tie Y, Jiang H, Sun ZX and Zheng XF: A novel method to monitor the expression of microRNAs. Mol Biotechnol 32: 197-204, 2006.

23. Jiang J, Lee EJ, Gusev Y and Schmittgen TD: Real-time expression profiling of microRNA precursors in human cancer cell lines. Nucleic Acids Res 33: 5394-5403, 2005.

24. Ho SY, Wu WJ, Chiu HW, Chen YA, Ho YS, Guo HR and Wang YJ: Arsenic trioxide and radiation enhance apoptotic effects in HL-60 cells through increased ROS generation and regulation of JNK and p38 MAPK signaling pathways. Chem Biol Interact 193: 162-171, 2011.

25. Zhang J and Bowden GT: Activation of p38 MAP kinase and JNK pathways by UVA irradiation. Photochem Photobiol Sci 11: 54-61, 2012.

26. Shin C, Nam JW, Farh KK, Chiang HR, Shkumatava A and Bartel DP: Expanding the microRNA targeting code: Functional sites with centered pairing. Mol Cell 38: 789-802, 2010.

27. Kashkar H: X-linked inhibitor of apoptosis: A chemoresistance factor or a hollow promise. Clin Cancer Res 16: 4496-4502, 2010.

28. Owens TW, Foster FM, Valentijn A, Gilmore AP and Streuli CH: Role for X-linked Inhibitor of apoptosis protein upstream of mitochondrial permeabilization. J Biol Chem 285: 1081-1088, 2010.

29. Ward JF: DNA damage produced by ionizing radiation in mammalian cells: Identities, mechanisms of formation, and reparability. Prog Nucleic Acid Res Mol Biol 35: 95-125, 1988

30. Kraemer A, Anastasov N, Angermeier M, Winkler K, Atkinson MJ and Moertl S: MicroRNA-mediated processes are essential for the cellular radiation response. Radiat Res 176 575-586, 2011.

31. Li B, Shi XB, Nori D, et al: Down-regulation of microRNA $106 \mathrm{~b}$ is involved in p21-mediated cell cycle arrest in response to radiation in prostate cancer cells. Prostate 71: 567-574, 2011.
32. Bhoumik A, Lopez-Bergami P and Ronai Z: ATF2 on the double - activating transcription factor and DNA damage response protein. Pigment Cell Res 20: 498-506, 2007.

33. Breitwieser W, Lyons S, Flenniken AM, Ashton G, Bruder G, Willington M, Lacaud G, Kouskoff V and Jones N: Feedback regulation of p38 activity via ATF2 is essential for survival of embryonic liver cells. Genes Dev 21: 2069-2082, 2007.

34. Hai T and Hartman MG: The molecular biology and nomenclature of the activating transcription factor/cAMP responsive element binding family of transcription factors: Activating transcription factor proteins and homeostasis. Gene 273: 1-11, 2001.

35. Kanzawa T, Iwado E, Aoki H, Iwamaru A, Hollingsworth EF, Sawaya R, Kondo S and Kondo Y: Ionizing radiation induces apoptosis and inhibits neuronal differentiation in rat neural stem cells via the c-Jun NH2-terminal kinase (JNK) pathway. Oncogene 25: 3638-3648, 2006.

36. Kumar P, Miller AI and Polverini PJ: p38 MAPK mediates gamma-irradiation-induced endothelial cell apoptosis, and vascular endothelial growth factor protects endothelial cells through the phosphoinositide 3-kinase-Akt-Bcl-2 pathway. J Biol Chem 279: 43352-43360, 2004.

37. Marais R, Wynne $J$ and Treisman R: The SRF accessory protein Elk-1 contains a growth factor-regulated transcriptional activation domain. Cell 73: 381-393, 1993.

38. Driák D, Osterreicher J, Reháková Z, Vilasová Z and Vávrová J: Expression of phospho-Elk-1 in rat gut after the whole body gamma irradiation. Physiol Res 57: 753-759, 2008.

39. Gordon S, Akopyan G, Garban H and Bonavida B: Transcription factor YY1: Structure, function, and therapeutic implications in cancer biology. Oncogene 25: 1125-1142, 2006.

40. Eckelman BP, Salvesen GS and Scott FL: Human inhibitor of apoptosis proteins: Why XIAP is the black sheep of the family. EMBO Rep 7: 988-994, 2006.

41. Datta R, Oki E, Endo K, Biedermann V, Ren J and Kufe D: XIAP regulates DNA damage-induced apoptosis downstream of caspase-9 cleavage. J Biol Chem 275: 31733-31738, 2000.

42. Park SY, Lee JH, Ha M, Nam JW and Kim VN: miR-29 miRNAs activate p53 by targeting p85 alpha and CDC42. Nat Struct Mol Biol 16: 23-29, 2009.

43. Cui F, Li X, Zhu X, Huang L, Huang Y, Mao C, Yan Q, Zhu J, Zhao W and Shi H: MiR-125b inhibits tumor growth and promotes apoptosis of cervical cancer cells by targeting phosphoinositide 3-kinase catalytic subunit delta. Cell Physiol Biochem 30: 1310-1318, 2012

44. Liu L, Yu X, Guo X, Tian Z, Su M, Long Y, Huang C, Zhou F, Liu M, Wu X, et al: miR-143 is downregulated in cervical cancer and promotes apoptosis and inhibits tumor formation by targeting Bcl-2. Mol Med Rep 5: 753-760, 2012. 